\title{
Editorial
}

\section{Combinatorial Optimisation}

\section{Associate Editors: Kathryn Dowsland and Bill Dowsland}

The Editors are pleased to offer this opportunity for the associate editors for Combinatorial Optimisation to outline their domain, and seek contributions from potential authors.

Combinatorial Optimisation $(\mathrm{CO})$ involves choosing one or more options from a set of possibilities in such a way as to optimise one of more objectives. Thus it covers a diverse range of practical problems arising across the range of business, service, and leisure activities and includes problems in scheduling, routing, location, allocation, space utilisation etc. It is therefore not surprising that such problems have becin of interest to those in Opcrational Research for many years.

Although there are some examples that can be solved 10 optimality with relatively litle, computational effort, the majority share with the travelling salcsman problem, the property that they are easy to state but very difficult to solve, due to the rapid explosion in the number of potential solutions as the size of the problem increases. Solution tcchniques can be broadly divided into exact approaches that guarantec optimality, and lieuristics, that take the more pragmatic approach of secking out good, but not necessarily optimal, solutions. The former are usually based on mathonratical modcls, sucl as integer programming, or graphs and networks, while the latter range from simple greedy coustruction approaches 10 sophisticated searcl mothods including local search, evolutionary algorithms and constraint logic programming.

Given the wide range of practical $\mathrm{CO}$ problems, and the rapid growtl and development in both exact and heuristic solution approacles it is perhaps surprising that since taking over the sub editorship 18 montlis ago we have not had a single submission in this area. One reason that las been suggested to us is that the field is too technical. While we agrec that this is true of many of the new dcvelopments in cxact solution approaches, and that many successful lieuristic approaches involve a level of techuical detail not suited to a publication sucl as OR Insiglı, we fecl that there are sevcral categorics of article that would be particularly appropriate. Thesc are:

- Papers describing situations where the most suitable approach has been found to be the application of a relativcly simple licuristic. This may be due to the nature of the problem itself, or 10 the characteristics of the environment in which it is to be solved. An example of such a paper is the description by Thompson (1999) of the way in whiclu the schedule for the 1999 Rugby Union World Cup was devised given the often conflicting objectives of teams, fans, and broadcasters.

- Papers outlining effective solutions based on standard solution approaches, but involving interesting modelling issucs. For cxample the paper of Hobbs and Ncebc (1994) describing a distribution problem in the coal industry in which considerable savings resulted from the implementation of on off-the-shelf IP solution approacl.

- Papers describing implementations based on combinatorial optimisation tecluniques, where the focus of the paper is on the problem analysis and implementation issues, and the way in which they influenced the choice of approach. An example is the description of a decision support system 10 aid the planning of laboratory visits given by Adlakha and Arsham (1997).

- Introductory tutorial papers describing models or techniques, particularly those with a proven success rate in solving real problens, such as the tutorial paper on 


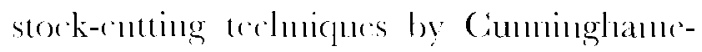
Gicoul 1992).

As well as anticles in these fon categonies we womld welcome any other contributions with a combitatorial optimisation flasom that fall within the rditorial guidelines of the jomrnal. When subniting vour paper, please lemember to address the genceal aims of OR lusight as detailed on the batk page, tegether with formatting instructions.

Please send any electomic copy of papers on Combinatorial Optimisation to Kathryn Dowsland or Bill Dowsland via w.h.dowsland(obleconnect.com.

We look forward to receiving your articles.

Adlakhat: Arshan H 1997 , Soheduling 'Travelling Inspecers, OR Insigh 10, 1, 2(1)-27.

Ciminghame-Green R 1992, Cut out Waste! OR Insight, 5, 3, 47.

Hobles.J, Necbe A 1994, Contracting for Coal, OR Insigh 8,1, 28-31.

Thompsom J M 1999: Kicking T'inctabling Problems into Touch - Scheduling the Rugby World Cup, OR Insighl, 12,3, 715. 